\title{
INFLUÊNCIA DA CONCENTRAÇÃO E DO TIPO DE LÍQUIDO IÔNICO NA PARTIÇÃO DE ALFA-LACTALBUMINA EM SISTEMAS AQUOSOS BIFÁSICOS
}

\author{
A. A. BALBUENO ${ }^{1}$, M. PIGNATA ${ }^{2}$, M. P. MIRANDA ${ }^{1}$, R. C. S. SOUSA ${ }^{1}$, R. C. F. BONOMO e \\ G. T. DUTRA ${ }^{1}$ \\ ${ }^{1}$ Universidade Federal de Viçosa, Departamento de Química e Engenharia Química \\ ${ }^{2}$ Universidade Estadual do Sudoeste da Bahia, Departamento de Tecnologia Rural e Animal \\ E-mail para contato: rita.sousa@ufv.br
}

\begin{abstract}
RESUMO - Sistemas aquosos compostos por líquido iônico (LI) e fosfato de potássio foram utilizados neste trabalho para extrair a alfa-lactalbumina do soro de leite. Os efeitos da concentração de $\mathrm{LI}$ e do tipo de $\mathrm{LI}\left(\mathrm{C}_{4} \mathrm{minCl}\right.$ e $\left.\mathrm{C}_{2} \mathrm{minCl}\right)$ foram investigados. Para preparo dos sistemas, as quantidades de LI e sal foram determinadas a partir de dados de equilíbrio de fases disponíveis em literatura. Após a pesagem dos componentes, os tubos foram agitados, centrifugados e deixados em repouso na temperatura de trabalho. A quantificação da proteína em cada fase foi realizada por espectrofotometria. Resultados experimentais mostraram que até $84,9 \%$ de proteína puderam ser extraídos para a fase rica em $\mathrm{C}_{2} \mathrm{minCl}$ e até $62,5 \%$ para $\mathrm{C}_{4}$ minCl. Os valores de $\mathrm{K}$ variaram de 2,8 a 5,6 para $\mathrm{C}_{2} \operatorname{minCl}$ e de 4,7 a 5,2 para $\mathrm{C}_{4} \operatorname{minCl}$. Este novo processo de extração é sugerido por ter importante aplicação na separação de proteínas.
\end{abstract}

\section{INTRODUÇÃO}

O soro do leite é um efluente da indústria de laticínios, proveniente da fabricação de queijo, sendo rico em proteínas que possuem excelentes propriedades funcionais e nutricionais, sendo alvo de constantes pesquisas nas áreas de engenharia química, engenharia de alimentos, biomédicas, farmácia, entre outras ciências. O desenvolvimento de estratégias de mercado e o advento de novas tecnologias têm permitido aproveitar melhor o soro nos processos industriais, tanto como matéria prima de formulações, como na concentração e separação de seus componentes.

O soro é composto aproximadamente por $93 \%$ de água, $5 \%$ de lactose e $0,9 \%$ de proteínas, $0,3 \%$ de gordura, $0,2 \%$ de ácido láctico e pequenas quantidades de vitaminas. As principais proteínas do soro de leite são $\alpha$-lactalbumina ( $\alpha$-la), $\beta$-lactoglobulina $(\beta-\lg )$, glicomacropeptídeo (GMP), albumina do soro bovino (BSA), imunoglobulinas, lactoferrina e lactoperoxidase (Rodrigues, 2001).

A técnica de extração líquido-líquido utilizando sistemas aquosos bifásicos (SAB) oferece diversas vantagens para extração de biomoléculas já que é um sistema econômico e eficiente, possui curto tempo de processo, baixo consumo de energia e possibilidade de aplicação em grande escala (Ventura et al., 2011; 2009). 
Os $\mathrm{SAB}$ se formam quando um polímero solúvel em água e uma substância de baixo peso molecular (normalmente um sal inorgânico) ou dois tipos de polímeros solúveis em água se dissolvem em solução aquosa acima de suas concentrações críticas (Liu et al., 2011).No entanto, a maioria dos polímeros utilizados nos SAB convencionais apresenta alta viscosidade (Perumalsamy et al., 2007), logo, as soluções que são formadas são, geralmente, opacas, atrapalhando as análises dos compostos extraídos do sistema. Atualmente estão sendo muito utilizados os líquidos iônicos (LI) em substituição a esses polímeros.

Os LI são considerados os novos tipos de "solventes verdes" já que têm propriedades únicas, tais como: não-inflamabilidade, pressão de vapor negligenciável, forte poder de solubilização e estabilidade química e térmica (Wei e Ivaska, 2008).

Assim, considerando o alto custo de descarte do soro e seu alto valor nutricional, é interessante o estudo de seu uso e aproveitamento de seus componentes. O objetivo deste trabalho foi estudar a extração da alfa lactalbumina ( $\alpha$-la) do soro de leite, em sistemas aquosos bifásicos constituídos pelo cloreto de 1-butil-3-mitelimidazólio $\left(\mathrm{C}_{4} \mathrm{mimCl}\right)$, água e sal inorgânico fosfato de potássio.

\section{1. $\alpha$-la do soro de leite}

As proteínas do soro correspondem a $20 \%$ das proteínas do leite e possuem várias propriedades nutricionais, funcionais e tecnológicas. As principais proteínas presentes, representando cerca de $90 \%$ das proteínas do soro, são: a alfa-lactoalbumina ( $\alpha$-la), a betalactoglobulina ( $\beta$-lg) e o glicomacropeptídeo (GMP).

A $\alpha$-la possui duas variantes genéticas (A e B), porém somente a variante genética B é encontrada em leites de raças bovinas ocidentais. Ela contém 123 resíduos de aminoácidos (Sgarbieri, 2005). Esta proteína tem alta afinidade pelo $\mathrm{Ca}^{+2}$ e outro íons metálicos, como $\mathrm{Zn}^{+2}, \mathrm{Mn}^{+2}, \mathrm{Cd}^{+2}, \mathrm{Cu}^{+2}, \mathrm{Al}^{+2}$ (Segawa e Sugai, 1983).

Por ser rica em triptofano, a $\alpha$-la é apropriada para a elaboração de alimentos infantis por não induzir reações alergênicas, e é muito semelhante à do leite humano (Monteiro, 2005). Desempenha função importante na prevenção da úlcera gástrica, causada por etanol absoluto e por estresse (Sgarbieri, 2005). Em pH adequado e presença de ácido oléico, a $\alpha$-la polimeriza-se e adquiri a propriedade de apoptose, sendo capaz de destruir células cancerígenas ou células jovens não diferenciadas sem ter ação sobre células adultas normais (Eugene e Berliner, 2000).

\subsection{Sistemas aquosos bifásicos (SAB) baseados em líquidos iônicos}

A extração líquido-líquido é uma técnica muito utilizada em processos industriais. Entretanto, proteínas, organelas e fragmentos celulares, ácidos nucléicos ou mesmo células inteiras podem sofrer danos irreparáveis quando submetidas a tal processo, exigindo técnicas alternativas quando se deseja sua purificação (Pessoa Jr. e Kilikian, 2005).

Os Sistemas Aquosos Bifásicos (SAB) são definidos, genericamente, como sistemas de 
duas fases líquidas imiscíveis em que o solvente principal é a água (Zaslavsky, 1992). Eles se formam quando um polímero solúvel em água e uma substância de baixo peso molecular (normalmente um sal inorgânico) ou dois tipos de polímeros solúveis em água se dissolvem em solução aquosa acima de suas concentrações críticas (Liu et al., 2011). As duas fases aquosas são formadas com diferentes composições. Os solutos distribuem-se entre as duas fases de acordo com sua afinidade relativa por cada fase (Ventura et al., 2011). Em geral, apresentam grande quantidade de água em ambas as fases, fazendo com que sejam meios muito pouco agressivos a moléculas como enzimas, por exemplo.

Os SAB são reconhecidos como sistemas econômicos e eficientes e oferecem muitas vantagens como: curto tempo de processo, baixo consumo de energia e possibilidade de aplicação em grande escala. Além disso, os SAB têm sido muito utilizados na recuperação e purificação de proteínas (Ventura et al., 2011; 2009).

\subsection{Líquidos iônicos}

A maioria dos polímeros utilizados nos $\mathrm{SAB}$ convencionais apresenta alta viscosidade (Perumalsamy et al., 2007), logo, as soluções que são formadas são, geralmente, opacas. Isto pode atrapalhar nas análises dos compostos extraídos do sistema. Com isso, nos últimos anos o estudo da utilização de SAB baseados em líquidos iônicos (LI), constitui uma área emergente e que está em franco crescimento atualmente, pois estes compostos têm grande potencial como possíveis substitutos para os solventes orgânicos convencionais. Eles têm sido aplicados em processos de biopurificação e bio-extração (Welton, 1999).

Os LI são sais compostos por íons grandes, um cátion orgânico relativamente grande e um ânion orgânico ou inorgânico relativamente pequeno, que não formam uma rede cristalina bem definida, e assim permanecem líquidos à temperatura ambiente ou perto desta. Eles apresentam uma fraca interação interiônica, a qual resulta em uma baixa energia do retículo cristalino e baixa temperatura de fusão, o que os difere dos sais comuns (Cassol, 2007). Eles têm aplicação química e bioquímica incluindo sínteses químicas, transformações biocatalíticas, projetos de dispositivos eletroquímicos e processos de separação (Pandy, 2006; Wasserscheid e Welton, 2003).

A literatura mostra que os experimentos que testaram os SAB baseados em LI obtiveram bons resultados na extração de biomoléculas (Ventura et al., 2011; Claudio et al., 2010; Pei et al., 2009; Du et al., 2007. No entanto, há ainda pouco estudo a respeito do comportamento de partição de proteínas do soro de leite em SAB baseados em LI. Com isso, neste trabalho foi feito um estudo envolvendo sistemas compostos por $\mathrm{C}_{4} \operatorname{minCl}$ a fim de se obter novas informações acerca da capacidade de promover a formação de SAB e extrair a $\alpha$ la do soro do leite.

\section{MATERIAL E MÉTODOS}

No experimento realizado foram utilizados os líquidos iônicos cloreto de 1-butil-3metilimidazólio cloreto $\left(\mathrm{C}_{4} \mathrm{mimCl}\right)$ e 1-etil-3-metil-imidazolio cloreto $\left(\mathrm{C}_{2} \mathrm{minCl}\right)$, adquiridos da Sigma Aldrich e a $\alpha$-la do soro de leite adquirida da Davisco Food Ingredientes 
International (Eden Praire, EUA). Para a formação do sistema, utilizou-se juntamente com os líquidos iônicos, o sal inorgânico, fosfato de potássio e água deionizada. Os diagramas de equilíbrio para $\mathrm{C}_{4} \mathrm{minCl}$ foram obtidos em literatura (Neves, 2009) e as concentrações utilizadas foram $15,75 \%, 17,69 \%$ e $21,36 \%(\mathrm{~m} / \mathrm{m})$. Para $\mathrm{C}_{2} \mathrm{minCl}$, os dados de equilíbrio foram determinados experimentalmente em laboratório. As curvas binodais foram determinadas pelo método turbidimétrico (Albertsson, 1986). As linhas de amarração foram obtidas utilizando o método gravimétrico descrito por Merchuk et al. (1998).

Os sistemas foram preparados em tubos de centrifuga graduados e calibrados. Após pesagem dos componentes (BEL Engineering, M 214 A), os SAB foram centrifugados (FANEM, Excelsa II 206 BL) e, então, deixados em repouso por aproximadamente 12 horas em estufa (FANEM, 502) a temperatura de $25^{\circ} \mathrm{C}$, para que o equilíbrio fosse atingido. Após alcançado o equilíbrio, o volume e a altura de cada fase foram medidos. Uma alíquota de cada uma das fases resultante foi coletada com o auxílio de uma seringa. A determinação da concentração de proteína nas fases foi feita em espectrofotômetro (Agilent, 8453) O coeficiente de partição foi calculado pela razão entre as concentrações de proteína na fase superior e inferior.

$$
K=C_{\text {sup }} / C_{\text {inf }}
$$

onde $\mathrm{C}_{\text {sup }}$ e $\mathrm{C}_{\mathrm{inf}}$ representam, respectivamente, a concentração da proteína na fase superior (rica em LI) e na fase inferior (rica em sal inorgânico).

Para selecionar o SAB com a melhor capacidade de purificação das proteínas, foi calculada uma recuperação teórica $(\mathrm{y}, \%)$ na fase superior por meio da seguinte equação:

$$
y(\%)=100 /[1+(1 / R . K)]
$$

sendo $\mathrm{R}$ a razão entre os volumes da fase superior e inferior do sistema SAB em estudo.

\section{RESULTADOS E DISCUSSÃO}

\subsection{Determinação do coeficiente de partição de $\alpha$-la em $\mathrm{C}_{4}$ minCl}

A Tabela 1 apresenta o valor de $\mathrm{K}$ para $\alpha$-la nos $\mathrm{SAB}$ baseados no $\mathrm{LI}\left(\mathrm{C}_{4} \mathrm{minCl}\right)$ e no sal fosfato de potássio.

Tabela 1 - Coeficiente de partição $(\mathrm{K})^{*}$ e recuperação teórica (y) ${ }^{*}$ de $\alpha$-la em SAB baseados em $\mathrm{C}_{4} \mathrm{mimCl}$

\begin{tabular}{|c|c|c|}
\hline Concentração LI & K & Recuperação teórica (\%) \\
\hline $15,75 \%$ & 5,63 & 62,54 \\
\hline $17,69 \%$ & 4,94 & 37,81 \\
\hline $21,36 \%$ & 4,70 & 20,77 \\
\hline
\end{tabular}

*Os valores apresentados na tabela são a média das duas repetições realizadas.

O mecanismo que rege a partição de proteínas em SAB compostos por LI ainda não é 
totalmente compreendido (Pei et al., 2009). A partição pode ser conduzida por uma combinação de interação hidrofóbica, interações electrostáticas e efeito de precipitação salina. Portanto, diversos fatores a afetam como: a natureza e a concentração do LI, os sais de formação de fases, o pH, a temperatura, a massa molar e a hidrofobicidade da superfície das proteínas.

Os valores de $\mathrm{K}$ encontrados foram similares aos de outros trabalhos reportados na literatura. Chen (1992) estudou a partição e separação de $\alpha$-la e beta-lactoglobulina em PEG (polietilenoglicol) utilizando um sistema aquoso de duas fases com fosfato de potássio e obteve valores de coeficiente de partição na faixa de 1 a 7. Mokhtarani et al. (2011) também estudaram a partição das mesmas proteínas em sistemas aquosos de duas fases de polivinilpirrolidona e fosfato de potássio e obtiveram valores dentro da faixa de 1 à 7 . Silva et al. (2009) em seu artigo de partição da proteína GMP em sistemas aquosos de duas fases obtiveram valores de $\mathrm{K}$ dentro da faixa de 2 a 9.

\subsection{Determinação do coeficiente de partição de $\alpha$-la em $\mathrm{C}_{2} \mathrm{minCl}$}

A Tabela 2 apresenta o valor de $\mathrm{K}$ para $\alpha$-la nos $\mathrm{SAB}$ baseados no $\mathrm{LI}\left(\mathrm{C}_{2} \mathrm{minCl}\right)$ e no sal fosfato de potássio.

Tabela 2 - Coeficiente de partição $(\mathrm{K})^{*}$ e recuperação teórica (y) ${ }^{*}$ de $\alpha$-la em SAB baseados $\mathrm{em}_{2} \mathrm{mimCl}$

\begin{tabular}{|c|c|c|}
\hline Concentração LI & K & Recuperação teórica (\%) \\
\hline & 2,76 & 73,40 \\
\hline & 5,31 & 84,15 \\
\hline & 5,64 & 84,93 \\
\hline
\end{tabular}

* Os valores apresentados na tabela são a média das duas repetições realizadas.

O ponto isoelétrico $(\mathrm{pI})$ da $\alpha$-la é 4,8 (Sgarbieri, 2004). Nos experimentos de extração, o $\mathrm{pH}$ do sistema foi 6,8 para $\mathrm{C}_{4}$ mimCl e 7,5 para $\mathrm{C}_{2}$ minCl. Assim, estes valores de $\mathrm{pH}$ são maiores que o pI. Como neste valor de $\mathrm{pH}$ a proteína está negativa, a interação entre o cátion imidazólio e os resíduos negativos da superfície da proteína é provavelmente a força motriz para a extração.

Com o aumento da concentração do LI, houve uma maior partição da $\alpha$-la para a fase superior para todos os sistemas estudados. À medida em que se aumenta a concentração de LI e sal, o número de interações envolvidas entre o LI e a proteína aumenta, resultando em um maior coeficiente de partição. Cammarata et al. (2001) investigaram o estado das moléculas de água em sistemas compostos por LI baseados em cátions 1-alquil-3-metilimidazol e vários ânions. Eles sugeriram que, por causa da presença de água, as associações de pontes de hidrogênio entre o cátion e o ânion do LI são parcialmente quebradas levando possivelmente ao aumento do número de íons livres e da mobilidade iônica na fase superior rica em LI. 


\section{CONCLUSÃO}

Neste trabalho, a extração de $\alpha$-la utilizando SAB compostos por LI se mostrou efetiva. Foi encontrado que até $84,9 \%$ de proteína puderam ser extraídos para a fase rica em $\mathrm{C}_{2} \mathrm{minCl}$ e até $62,5 \%$ para $\mathrm{C}_{4} \operatorname{minCl}$. Os valores de $\mathrm{K}$ variaram de 2,8 a 5,6 para $\mathrm{C}_{2}$ minCl e de 4,7 a 5,2 para $\mathrm{C}_{4}$ minCl. Comparados aos $\mathrm{SAB}$ tradicionais, os sistemas utilizando LI tem as vantagens de baixa viscosidade, pouca formação de emulsão, rápida separação de fases, entre outras. Os resultados obtios indicam novas possibilidades de uso de SAB baseados em LI para separação de biomoléculas.

\section{REFERÊNCIAS}

CAMMARATA, L.; KAZARIAN, S. G.; SALTER, P. A.; WELTON, T. Molecular states of water in room temperature ionic liquids, Phys. Chem. Chem. Phys. v. 3, p. 5192-5200, 2001.

CASSOL, C. C. Líquidos Iônicos em Processos de Extração Seletiva de Compostos Aromáticos, Nitrogenados e Sulfurados em Frações do Petróleo. Dissertação de Mestrado, Universidade Federal do Rio Grande do Sul, Instituto de Química, 2007.

CHEN. J.P. Partitioning and separation of $\alpha$-lactalbumin and $\beta$-lactoglobulin in PEG/potassium phosphate aqueous two-phase systems. J. of Ferment. Bioeng., v. 73, n. 2, p. 140-147, 1992.

ClÁUdiO, A. F. M.; FREIRE, M. G.; FREIRE, C. S. R.; SILVESTRE, A. J. D.; COUTINHO, J. A. P., Extraction of vanillin using ionic-liquid-based aqueous two-phase systems, Sep. Purif. Technol. v. 75, p. 39-47, 2010.

DU, Z.; YU, Y. L.; WANG, J. H. Extraction of proteins from biological fluids by use of an ionic liquid/aqueous two-phase system. Chem.-Eur. J., v. 13, p. 2130-2137, 2007.

EUGENE, A.; BERLINER, L. J. $\alpha$-lactalbumin: structure and function. FEBS Letters. v. 473, p. 269-274, 2000.

LIU, Y. YU, Y.L. CHEN M.Z. XIAO. X. Advances in aqueous two-phase systems and applications in protein separation and purification. Canadian Journal on Chemical Engineering and Technology, 2, 2011.

MOKHTARANI, B., MORTAHEB, H.R., MAFI, M., AMINI, M.H. Partitioning of $\alpha$-lactalbumin and $\beta$-lactoglobulin in aqueous two-phase systems of polyvinylpyrrolidone and potassium phosphate. J. Chromatography B, p. 721-726, 2011.

PANDY, S. Analytical applications of room-temperature ionic liquids: A review of recent efforts. Anal. Chim. Acta, 556, 38-45, 2006.

PEI, Y. JIANJI, W. WU, K. XUAN, X. LU, X. Ionic liquid-based aqueous two-phase extraction of selected proteins Separation and Purification Technology. Sep. Purif. Technol. v. 64, p. 288295, 2009.

PERUMALSAMY M., BATHMALAKSHMI A., MURUGESAN T. Experiment and correlation of liquid-liquid equilibria of an aqueous salt polymer system containing PEG6000 + sodium citrate. J. Chem. Eng. Data, v. 52, p. 1186, 2007. 
SEGAWA, T.; SUGAI, S. Interactions of divalent metal ions with bovine, human and goat $\alpha-$ lactoalbumina. Journal of Biochemistry. v. 93, p. 321-328, 1983.

SGARBIERI, V.C. Propriedades fisiológicas-funcionais das proteínas do soro de leite, Revista de Nutrição, 17 (4), 1-8, 2004.

SILVA, C.A.S., COIMBRA, J.S.R., ROJAS, E.E.G., TEIXEIRA J.A.C. Partitioning of glycomacropeptide in aqueous two-phase systems. J. Process Biochemistry, p. 1213-1216, 2009.

VENTURA, S. P. M.; SOUSA, S. G.; FREIRE, M. G.; LIMA, A. S.; COUTINHO, J. A. P. Design of ionic liquids for lipase purification. J. Chromatogr., B, 879, 679-2687, 2011.

VENTURA, S.P.M.; NEVES, C.; FREIRE, M.G.; MARRUCHO, I.M.; OLIVEIRA, J.; COUTINHO, J.A.P. Evaluation of anion influence on the formation and extraction capacity of ionic-liquid-based aqueous biphasic systems. J. Physical Chem. B, v. 113(27), p. 93049310, 2009.

WASSERSCHEID, P.; WELTON, T. Ionic liquids in synthesis; Wiley-VCH: Weinheim, Germany, 2003.

WEI, D.; IVASKA, A. Applications of ionic liquids in electrochemical sensors. Analytica Chimica Acta, v.607, n.2, p.126-135, 2008.

WELTON, T. Room-temperature ionic liquids solvents for synthesis and catalysis. Chemical Rev., v.99, p. 2071-2084, 1999.

ZASLAVSKY, B. Y. Aqueous Two-Phase Partitioning. New York: Marcel Dekker, 1995. 